\title{
Eyes wide shut? UK consumer perceptions of aviation climate impacts and travel decisions to New Zealand
}

Scott Allen Cohen ${ }^{\text {ab* }}$ and James E.S. Higham ${ }^{a}$

${ }^{a}$ Department of Tourism, School of Business, University of Otago, PO Box 56,

Dunedin, New Zealand. Email: james.higham@otago.ac.nz

${ }^{\mathrm{b}}$ School of Tourism, Bournemouth University, Dorset House, Talbot Campus, Poole, Dorset, BH12 5BB, UK. Email: scohen@bournemouth.ac.uk

*Corresponding author

\begin{abstract}
The purview of climate change concern has implicated air travel, as evidenced in a growing body of academic literature concerned with aviation $\mathrm{CO}_{2}$ emissions. This article assesses the relevance of climate change to long haul air travel decisions to New Zealand for United Kingdom consumers. Based on 15 semi-structured open-ended interviews conducted in Bournemouth, UK during June 2009, it was found that participants were unlikely to forgo potential travel decisions to New Zealand because of concern over air travel emissions. Underpinning the interviewees' understandings and responses to air travel's climate impact was a spectrum of awareness and attitudes to air travel and climate change. This spectrum ranged from individuals who were unaware of air travel's climate impact to those who were beginning to consume air travel with a
\end{abstract}


'carbon conscience'. Within this spectrum were some who were aware of the impact but not willing to change their travel behaviours at all. Rather than implicating long haul air travel, the empirical evidence instead exemplifies changing perceptions towards frequent short haul air travel and voices calls for both government and media in the UK to deliver more concrete messages on air travel's climate impact.

Keywords: climate change, air travel, $\mathrm{CO}_{2}$ emissions, impact perceptions, travel decisions

\section{Introduction}

This article addresses the relevance of climate change to long haul air travel decisions to New Zealand for United Kingdom consumers. Discourse concerning the reduction of emissions is considerable in Europe, with the European Union having set a goal of reducing $\mathrm{CO}_{2}$ by $20 \%$ (compared to base year 1990) by 2020 (Gössling \& Hall, 2008). The continued viability of the UK market is important to NZ tourism as the UK comprises the largest long haul market for NZ international arrivals (Ministry of Tourism, 2009a). Hence, it is particularly relevant to explore how perceptions of climate change and air travel may impact the sustainability of this key source market.

There has been an increasing body of academic literature concerned with the impact of air travel on global $\mathrm{CO}_{2}$ emissions (for instance Becken, 2007; Gössling \& Upham, 2009; Hares, Dickinson, \& Wilkes, 2009; Smith \& Rodger, 2009). In the world's weathier countries, 'the idea of taking one or more foreign holidays each year increasingly to a long-haul destination - has quickly been transformed from an aspiration to an expectation' (Shaw \& Thomas, 2006, p. 213). Air travel, however, has been identified as a rapidly growing contributor to overall $\mathrm{CO}_{2}$ emissions, with a single 
long haul flight exceeding annual per capita sustainable emission levels (Gössling et al. 2009). In comparison to tourism transport alternatives such as rail, road and sea-based passenger modes, air travel is furthermore the most harmful for the climate system (Gössling \& Peeters, 2007).

The contribution of aviation to total global $\mathrm{CO}_{2}$ emissions in 2005 was widely taken to be approximately 3.5\% (Smith \& Rodger, 2009). Aviation projections, however, forecast continued rapid growth, with average annual growth rates of $5.3 \%$ until 2023 (Gössling \& Peeters, 2007). As the only sector with continued unrestricted emissions growth (while other sectors meanwhile are required to reduce emissions), aviation is projected to emit $15-40 \%$ of total global $\mathrm{CO}_{2}$ by 2050 (Dubois \& Ceron, 2006; Gössling \& Peeters, 2007). As such, in the EU where emission reduction targets have been set (and may be raised), tourism development based on air travel has been accused of being in conflict with global emission reduction needs and pressure is mounting on the tourism industry to move towards a so-called 'sustainable emissions path’ (Gössling, 2009).

\section{Tourists' perceptions of air travel and climate change}

While it is well acknowledged scientifically that air travel impacts the global climate (Shaw \& Thomas, 2006), until recently, little socio-cultural research had been carried out on whether tourists are aware of the impact air travel has on the climate system and whether tourist patterns may change in response to this knowledge (Becken, 2007; Hares, et al., 2009). Gössling and Hall (2006) warned that one of the dangers of top-down modelling that attempts to predict tourist flows in relation to climatic and economic factors (for instance Lise \& Tol, 2002) is that the role of perceptions in travel 
decision-making remains ambiguous. Several key studies have since emerged that use a bottom-up approach to explore tourists' perceptions of air travel's climate impact (Becken, 2004, 2007; Donnelly, 2008; Gössling, Bredberg, Randow, Sandström, \& Svensson, 2006; Gössling, Haglund, Kallgren, Revahl, \& Hultman, 2009; Hares, et al., 2009; Shaw \& Thomas, 2006).

In the first of these studies, Becken (2004) surveyed how tourists and tourism academics in NZ and Australia perceived climate change as an issue for tourism, finding that awareness of tourism's contribution to climate change was low. Similar results were obtained by Gössling et al. (2006), who used questionnaires to survey international tourists to Zanzibar in situ on the importance of climate factors in their travel decisions and their awareness of tourism's contributions to climate change. Their conclusion that tourists were largely unaware of the consequences of travel for climate change was consistent with Shaw \& Thomas' (2006) findings from exploratory focus groups and semi-structured interviews with international students in the UK, for whom the climate impact of their frequent flying went largely unrecognised. Based on these initial case studies, Gössling and Peeters (2007) noted in their analysis of airline discourses on air travel and the environment that public knowledge of the environmental problems associated with air travel is relatively low.

Recently, evidence has emerged that tourists are possibly becoming more aware and concerned over air travel's $\mathrm{CO}_{2}$ emissions. Gössling et al.'s (2009) survey of Swedish air travellers' knowledge and attitudes to air travel, climate change and voluntary carbon offsetting confirms that whilst most perceived flying to be an unquestionable part of their lifestyle and found it 'irrelevant' to reduce personal air travel, approximately a quarter of the respondents expressed a willingness to fly less in 
order to mitigate emissions. In line with this finding, Gössling, Peeters and Scott (2008, p. 875) observed that 'pro-environmental concerns are clearly emerging among consumers, and may play a significant role in travel decisions in the future.'

Nonetheless, other recent studies present evidence that reinforces the dominant discourse that tourists are either relatively unaware of air travel's climate impact or unwilling to voluntarily mitigate their own air travel behaviour (Becken, 2007; Donnelly, 2008; Hares, et al., 2009). Using in situ focus groups of international tourists visiting NZ, Becken (2007, p. 351) found that limiting travel was unacceptable to the '(hyper) mobile tourists' involved in her research, and in turn, suggested that only major changes on a societal level would be sufficient to drive the behavioural change needed to reduce air travel's climate impact. Hares et al. (2009) concluded from focus groups with potential outbound UK tourists that respondents did not consider climate change in their thoughts and decisions when planning holidays, albeit several acknowledged air travel as a significant contributor to climate change. Finally, it has been reported that, despite environmental concerns, UK and German consumers value long haul travel to Australia too highly to adapt their air travel intentions (Donnelly, 2008).

Although considerable headway has been made in assessing tourists' perceptions of air travel and climate change, evidence of varying levels of climate concern across different cultural and temporal contexts suggests that knowledge of and response to air travel's climate impact is socio-culturally contingent and changing over time. Shaw and Thomas (2006, p. 214) highlighted the importance of keeping abreast of market-based perceptual shifts in climate concern when noting that 'the tracking of travel behaviour as well as opinions on the sustainability of air travel will be critical over the coming 
decade.' Unsurprisingly, the sustainability of tourism receipts to long haul destinations that are reliant on air travel has become increasingly topical.

Tourism stakeholders have begun to map the implications of regulatory policybased initiatives designed to both mitigate the growth of air travel and foster environmental attitudes encouraging tourists to change their air travel patterns (Gössling, et al., 2008; Ministry of Tourism, 2008). Indeed, Becken (2002, p. 127) was correct in forecasting that the unsustainable energy use associated with air travels means that 'remote countries that are focusing on tourism as a profitable and expanding industry, such as New Zealand, are in a delicate situation.' In NZ, where tourism accounts for nearly $10 \%$ of the economy, the Ministry of Tourism (2008) has identified as a key risk the potential in its major markets for shifts in consumer preference away from long haul travel.

\section{Long haul travel from the United Kingdom to New Zealand}

NZ's largest long haul market and second largest international market overall, the UK, like other European markets, consumes the most energy per capita through air travel to NZ because of geographical distance (Becken, 2002). The vast majority of international visitors to NZ arrive by air (Smith \& Rodger, 2009), with 285000 of these visitors in 2008 having been from the UK (Ministry of Tourism, 2009b). One return flight from the UK to $\mathrm{NZ}$ approaches half of an average UK citizen's annual total $\mathrm{CO}_{2}$ emissions and exceeds global annual per capita sustainable $\mathrm{CO}_{2}$ budget projections, asexemplified in the following approximation. 
It has been established that the effect of aviation emissions on climate change is greater than the $\mathrm{CO}_{2}$ emissions alone (Penner, Lister, Griggs, Dokken, \& McFarland, 1999). From Smith and Rodger (2009), it can be estimated that the $\mathrm{CO}_{2}$ emissions of one person flying from the UK to NZ return is 4.2 tonnes. Smith and Rodger (2009) attempted to account for the non- $\mathrm{CO}_{2}$ impacts of emissions from aviation on climate, and they cite Brand and Boardman (2008) who calculate that aviation impact multipliers can range from 1.5 to 4 . The figure of 4.2 tonnes of $\mathrm{CO}_{2}$ used here is therefore a lower bound on the estimate of the climate impact of such a flight. As an average UK citizen emits 9.5 tonnes of $\mathrm{CO}_{2}$ a year (Monbiot, 2007), excluding international travel, one return flight to NZ equates to approximately $44 \%$ of each UK citizen's yearly domestic $\mathrm{CO}_{2}$ emissions. Alternatively, based on a sustainable domestic emissions path of 3.5 tonnes of $\mathrm{CO}_{2}$ emitted globally per person per year (Gössling, et al., 2009), long haul air travel to NZ is equivalent to $120 \%$ of yearly sustainable emissions. In terms of personal contributions, Gössling et al. (2009, p. 2) thus concluded of air travel that 'there is hardly any other human activity that contributes to such substantial amounts of greenhouse gas emissions in a comparably short period of time.'

Aviation sector emissions have reportedly been widely publicised in the UK media as growing more rapidly than any other UK sector (Bows, Anderson, \& Footitt, 2009). Aviation $\mathrm{CO}_{2}$ emissions are likely to be accountable from 2011 through the EU Emission Trading System (Gössling, et al., 2009). Based on the UK government's own climate change target of not exceeding a $2^{\circ} \mathrm{C}$ temperature rise, and without rapid action to curtail aviation growth in the UK, all other sectors in the UK would have to almost completely decarbonise by 2050 to compensate for aviation as it is forecasted to ultimately account for the entire available $\mathrm{CO}_{2}$ budget for the UK economy (Bows, 
Anderson, \& Upham, 2006; Randles \& Mander, 2009). With substantial individual $\mathrm{CO}_{2}$ contributions from each European flight to NZ and increasing media comment in Europe on long haul air travel's climate impact (Smith \& Rodger, 2009), it is both timely and topical to assess consumer perceptions in the UK market on long haul air travel to NZ.

Whilst Becken (2007) examined perceptions on air travel and climate change of international tourists who had already chosen to travel to NZ, research on potential climate concerns associated with air travel to NZ has not been undertaken within its largest long haul market, the UK. Although UK consumer research has been conducted into climate change and general air travel decisions (Hares, et al., 2009) and perceptions towards long haul travel to Australia (Donnelly, 2008), the present study specifically explores the attitudes of UK consumers towards long haul travel to NZ, in light of growing media and scientific discourses on climate concern.

\section{Method}

The empirical material presented here is part of a broader study on potential climate change concern in NZ's long haul European markets. Whilst the positionality of the researchers is that of highly mobile individuals who feel that air travel emissions should be mitigated, the research was approached as non-activist wherein the aim was to elicit subjective perspectives. Empirical research was undertaken as part of one return air journey from NZ for which the field researcher chose to mitigate his personal emissions by voluntarily offsetting using a NZ based carbon sequestration scheme.

This article is based on 15 semi-structured open-ended interviews conducted in Bournemouth, UK during June 2009 while one of the authors was positioned as a 
visiting researcher at the School of Services Management, Bournemouth University. Whereas related studies into tourists' perceptions of air travel's climate impact have used surveys (Gössling, et al., 2006, 2009) or focus groups (Becken, 2007; Hares, et al., 2009) as their method of choice, the present work instead employed one-to-one openended interviewing respectively for its flexibility in exploring issues in detail as they arose during the process (Jennings, 2001) and because it reduced the influence of group norms on individual voices (Patton, 2002). The research used a snowball sampling technique that relied initially on key informants to help gain access to potential participants, both from within and outside of the university context. The only participant inclusion criterion for the study was that respondents self-defined their national identity as being from the UK. The researcher did, however, aim to access interviewees representing a relatively equal gender distribution across a broad age range, with a minimum age of 18 years. The interviews were digitally recorded and conducted on a one-on-one basis, with each lasting approximately thirty minutes to one hour.

At the outset of each interview, the study participant was asked the wider question of whether (s)he believed there is a human contribution to climate change and whether (s)he felt an individual sense of responsibility to try to reduce personal $\mathrm{CO}_{2}$ emissions. Although the remainder of each interview was then largely conversational, a loose interviewing schedule was employed that was primarily based around assessing the importance of climate change issues in broader travel decisions, and more specifically, past and potential long haul travel decisions to NZ. The relevance of the current global economic downturn as a related factor in decision-making processes was also accommodated in the interview process. The interviewees comprised seven females and eight males with ages that ranged from 18-63, with an average age of 38 (Table 1). 
Their occupations reflected five industry professionals, four university academics, three university administrators, two undergraduate students and one postgraduate student. The participants represented a range of education levels, as the highest education level that five of the respondents had completed was a high school degree, four had earned undergraduate degrees, four had Masters degrees and two had PhDs.

Since snowball sampling for the research was driven out of a university context, the interviewees mostly reflected a moderately affluent and well educated sociodemographic profile. While this collective profile proffered the opinions of individuals with cultural and material resources likely to make air travel accessible, the perspectives here did not give voice to sections of UK society of lesser privilege. The findings do confirm that the interviewees were relatively aeromobile, as they were unanimously past and/or present regular users of airplanes, with the majority of the interviewees having flown internationally at least once per year. Several return flights per year were not uncommon amongst the study participants. This included significant numbers of short haul intra-European air travel as well as long haul routings, spanning purposes of leisure, business and visiting friends and relatives (VFR). A few of the interviewees described reduced personal and professional air travel in response to the 2008 global financial crisis. Regular annual holidays employing international air travel were, nonetheless, the norm.

Following transcription, the authors separately immersed themselves in the empirical material and applied a thematic analysis approach in interpreting the interview transcripts (Patton, 2002). This approach involved reducing the empirical material into categories guided by the interviewees' narratives and the research aims, a process which allowed for the identification of emergent themes (O'Reilly, 2005). After triangulating 
the respective authors' interpretations, further joint interpretations allowed for the development of the empirical insights that follow.

Table 1

Summary profile of interview programme participants

\begin{tabular}{|lllll|}
\hline Pseudonym & Gender & Age & Occupation & Education level completed \\
\hline Cindy & Female & 42 & University administrator & High school \\
Jack & Male & 35 & Industry professional & Undergraduate \\
Grace & Female & 36 & University administrator & Masters \\
Jessica & Female & 48 & University administrator & High school \\
Ruby & Female & 41 & Industry professional & High school \\
Amy & Female & 30 & University academic & PhD \\
Hannah & Female & 48 & Postgraduate student & Masters \\
Oliver & Male & 30 & University academic & Masters \\
Thomas & Male & 38 & University academic & Masters \\
Harry & Male & 40 & Industry professional & Undergraduate \\
Daniel & Male & 18 & Undergraduate student & High school \\
Mia & Female & 21 & Undergraduate student & High school \\
James & Male & 63 & University academic & PhD \\
William & Male & 42 & Industry professional & Undergraduate \\
Lewis & Male & 39 & Industry professional & Undergraduate \\
\hline & & & & \\
\hline
\end{tabular}




\section{Climate concern in flying to New Zealand}

Even though many of the study participants expressed concern about the quantity of $\mathrm{CO}_{2}$ that would be emitted from personal air travel to $\mathrm{NZ}$, it was widely stated that climate concern would not prevent them from flying to NZ. NZ was perceived by the majority of the interviewees as a special destination and in some cases a potential trip to NZ was valued as a 'trip of a lifetime'. For instance, Harry (40), when asked if he would be concerned about the emissions from air travel to NZ, communicated a desire to be more resolute in mitigating his personal $\mathrm{CO}_{2}$ contribution, yet at the same time viewed a trip to NZ as extraordinary: 'I'd like to be a more resolved about the whole thing, but a trip to NZ - that's a trip of a lifetime. That's probably something that I'd only ever get to do once. And no, it [emissions] wouldn't stop me.'

Other participants, such as Cindy (42), suggested that even though one might be aware of the climate consequences of air travel to NZ, one would still go and try to ignore the climate impact: 'It would matter a bit but I think if I really wanted to go I'd still do it and I wouldn't worry too much about the consequences.' This evidence is consistent with Donnelly's (2008) conclusion that climate concern among UK consumers is 'momentarily buried', as long haul travel is perceived as too valuable to forgo.

In contrast to long haul travel to NZ, a number of the respondents implicated frequent short haul air travel within the UK and Europe as problematic. Hannah (48) noted how she would prefer to see regulation fall upon short haul as opposed to long haul routings: 
I would hate to think that the long haul destinations get hit. I'd like to see that keep going and it's the smaller, low cost flights that people just hop around for the sake of it. You don't have to hop off every weekend to a different destination in Europe.

Gössling and Hall (2008, p. 153) observed that low cost short haul air travel 'creates hypermobile travel patterns, while spreading the idea that travel is possible at virtually no financial cost.' Impulsive short haul air travel as a perceived problem area was expounded upon by Amy (30):

The boom of the budget airline made flying an option whereas traditionally you wouldn't have because it was too expensive. Certainly for domestic flights and even short haul to Europe. And suddenly we're all zooming off to places we didn't know we'd probably go to. I think it needs regulation.

Whereas Hares et al. (2009) found their participants to have a positive outlook on low cost airlines, the current research thus evidenced changing perceptions of frequent short haul air travel.

Returning to the focus of long haul air travel and highlighting that it would be myopic to only consider air travel through a lens of tourism, as air travel links to NZ are also important for other reasons such as VFR and commerce, amongst others, Lewis (39) expressed an ambition to visit friends and family in NZ one day, despite recognition of the associated air travel emissions: 'The emissions must be fairly horrendous from here. But I've got friends and family who live out there and I'd love to go. That is definitely one of my ultimate aims.' Lewis gives voice to the importance of maintaining transnational connections that increasingly link friends and family members through multiple ties wherein personal relationships have been extended beyond the borders of nation states (Vertovec, 2009). 
The willingness of the study participants to fly to NZ, however, was not without its price sensitivities. James (63) noted that whilst he would not be concerned about personal emissions from flying to NZ, he would redirect his holidays to more affordable destinations closer to home if $\mathrm{CO}_{2}$ taxes drove the price of flying to $\mathrm{NZ}$ up significantly: 'It wouldn't affect my decision to go or not go. It would be nice to go when I retire, but if the taxes and prices were to go up considerably, that would probably almost preclude ever going.'

Finally, a few of the interviewees not only expressed a definite concern about the emissions generated from air travel to NZ, but also linked their concern to shifts in travel decision making. For Oliver (30), a trip to $\mathrm{NZ}$ was no longer desirable as $\mathrm{CO}_{2}$ 'guilt' redirected his travel ambitions closer to the UK:

Coming back from Australia two years ago, I felt guilty about the carbon. I'd be reluctant to go to New Zealand. I can find fantastic beaches in Europe, I can find fantastic mountains in Europe, I can find fantastic glaciers in Europe and I can find sheep in Europe.

Oliver's redirection to closer holiday destinations within Europe with competing physical resources represents potential (re)branding and market positioning challenges for the NZ tourism industry. This perspective, however, was the minority as most of the study participants were unwilling to forgo a holiday in NZ because of the air travelemissions. The findings thus suggest that climate concern amongst UK consumers over air travel's emissions does not (yet) significantly threaten the sustainability of NZ's largest long haul market. 


\section{Spectrum of attitudes towards air travel and climate concern}

The perceptions of the study participants towards air travel emissions and long haul air travel to NZ were underpinned by a more general spectrum of awareness and attitudes to air travel and climate change. This spectrum ranged from individuals who were unaware of air travel's climate impact, to those who were aware of the impact but not willing to change their travel behaviours, and through to several interviewees who were aware of air travel's climate impact but were beginning to show signs of consuming air travel with a conscience.

\section{Unaware of air travel's climate change impact}

A few of the respondents were largely unaware of air travel's contribution to climate change. For Cindy (42), the climate impact of airplanes seemed similar to cars and trains, and she generally demonstrated a low level of knowledge about the significance of air travel's emissions and the relative emissions of using alternative forms of transport:

I would probably see planes in the same way I would see cars and trains. I would think that they must have some impact on climate change, but how much I'm not really sure. What will happen because of carbon through planes? I don't really know what will happen, so therefore that's maybe why I'm not giving it a great deal of thought. I'm not really sure of the other types of travel that I could use that would be better with regards to climate change.

Cindy's low awareness equated to low climate concern, and was consistent with previous studies reporting low consumer awareness of air travel's climate impact (Becken, 2004, 2007; Gössling, et al., 2006; Shaw \& Thomas, 2006).

One of the study's most aeromobile participants, who flies annually to Australia, evidenced a lack of knowledge about the significance of air travel's $\mathrm{CO}_{2}$ contribution in 
comparison to everyday domestic mitigation strategies such as recycling. In the case of Thomas (38), for whom climate concern plays virtually no role in both his everyday life and travel decision-making, it was hoped that domestic responses to climate change might offset personal air travel emissions.

What difference can I make? Next I'm taking off to Australia. The thought about what my emissions are going to be doesn't really click with me, because I want to go. I'd hate to lose my trips to Australia and I'd hate to pay double for them. Can I not do enough on a local level that I won't have to forgo those kinds of luxuries?

Thomas was clearly unaware that air travel emissions have the potential to dwarf domestically generated emissions in terms of relative contributions to climate change. Respondents often emphasised domestic climate change mitigation strategies, such as reducing plastic carrier bags at the supermarket or recycling, in the hope that these measures would justify continued personal emissions through air travel.

\section{Aware but will not change behaviour}

Several of the study participants were aware of air travel's climate impact, but unwilling to modify their air travel behaviour in response. A tension emerged in their narratives in which there was reluctance to forgo perceived positive benefits made accessible by air travel, in most cases through tourism, in order to reduce personal emissions. Participants who attached too high of an importance to their holidays to consider adapting them because of climate change mirrored the findings of Hares et al. (2009). Shaw and Thomas (2006) called for future empirical research into how air travellers perceive the benefits of air travel and weigh these against its consequences for the environment. Indeed, this study teases out a paradox in which many respondents 
were remorseful of their air travel emissions, but nonetheless continued their travel patterns. When asked what she thought of air travel's emissions, Ruby (41) expressed:

Although it's got a huge impact and you're aware of it, if you want to get somewhere long distance, it's easier. I want to see more of the world. So if I had the money, I would be doing it, despite knowing that it was damaging the world. That's what I mean about the contradiction. You kind of try to put it back of your mind and try not to worry about it.

Having identified her own contradiction, Ruby evinces how air travellers may struggle with their conscience over $\mathrm{CO}_{2}$ emissions, but ultimately sweep the guilt aside. For another interviewee, Harry (40), his awareness of the climate impact from his air travels is a source of personal discontent, but he is not troubled enough yet by the impact to alter his air travel decisions:

I do see the [climate] impact and I would get on an airplane and go on a long haul flight because I want to travel. It's convenience, but at the same time, I'm not happy about the fact that it's not particularly good for the environment. But not unhappy enough yet, that's the truth.

Harry volunteered with concern that he hoped it would not [but may] take a catastrophic event induced by climate change to bring the guilt stemming from his personal emissions to a tipping point where he reined in his air travels.

The question has been raised as to why environmental awareness does not seem to translate to pro-environmental attitudes and behaviours in the context of holidays and climate change (Hares, et al., 2009). In the eyes of one of the study's younger respondents, Mia (21), the repercussions of climate change did not seem immediate and pressing enough to warrant significant personal responses:

It doesn't seem like it's going to be a problem in my lifetime. I can understand why it's difficult for people to act on it because as important as it is, it's not something that is going to happen straight away. 
Sacrificing one's holiday now in order to mitigate climate problems occurring outside of one's lifetime was thus too abstract of a notion for some of the participants.

\section{Consuming air travel with a conscience}

A significant proportion of the interviewees were aware of air travel's climate impact and were beginning to show signs of consuming air travel with a "carbon conscience'. Randles and Mander (2009) concluded that although UK society is moving towards more frequent flying, there are 'flickerings' of evidence that climate concern may lead to reduced air travel. The material in the current study thus describes a more complex playing field than past studies that have described consumers as either unaware of air travel's climate change impact (Becken, 2004; Gössling, et al., 2006; Shaw \& Thomas, 2006) or largely aware but unwilling to modify their behaviour (Hares, et al., 2009). For this study's climate concerned interview participants, recognition of air travel's climate change contribution had helped drive behavioural responses characterised by the avoidance of 'flippant' air travel. Grace (36) teased out the difference between what she perceived as frivolous air travel and conscientious air travel:

I don't like people being really flippant about it and not putting any thought into it at all. I would pick out the places that I really wanted to go to, but I would not

flippantly, just every single year take a long haul flight just because I could.

This perspective paralleled Becken's (2007, p. 362) finding that tourists may distinguish by value between 'legitimate holidays' and 'dispensable trips'.

A few of the participants described intentions to limit their future air travels because of climate change concern. In Jack's (35) case, the impact of each flight was 
held as important and he stressed a willingness to give up air travel entirely in the future if need be:

One flight does matter. I will try to limit the amount that I fly. I've always wanted to give to nature what I get out of it, and if that means I can't go and travel somewhere because it means that I'm going to mess the world up, I won't travel, simple as that.

In a more measured approached, Oliver (30), annually tracked his personal $\mathrm{CO}_{2}$ contribution with a carbon calculator, through which he saw in repeated years that his air travel emissions pushed him far beyond his goal of sustainable personal emission levels:

I plug my own usage into a carbon calculator. Once a year and I'm always very disappointed with myself. Flying has been my Achilles heel. I have now made a conscious decision that I'm happy if the rest of my life passes and I don't leave Europe.

Both of these respondents expressed a desire to largely avoid air travel and focus future holidays closer to or within the UK, where shorter travel distances would be more agreeable to alternative lower climate impact modes of transport such as train, bus or ferry.

Lastly, William (42) furthered a view that long haul air travel for tourism purposes had become excessive and wasteful:

I feel that tourism has reached its peak. I just don't believe that everyone should be flying all over the world to these different places. I think peoples' expectations have been raised now to the fact that they do believe they've got to go further and further afield to more exotic destinations where it used to be sort of the domain of the adventurous. Now it has become more of the domain of the mundane for people to go there.

Viewing long haul tourism as the 'domain of the mundane', rather than a source of status, supports Randles and Mander's (2009) suggestion that cultural capital through long haul tourism has become harder to come by as flying to exotic destinations has 
moved into the mass market. Cynical views towards travelling long distances for tourism is further evidence of shifting social perspectives towards air travel. Randles and Mander's (2009, p. 270) additional observation that the UK is on the cusp between increasing social acceptance of frequent flying on one hand and the "tipping of popular discourse against environmental and climate concerns on the other,' reflects a tension that was certainly exemplified in the present study.

\section{Clearer messages on air travel's climate impact}

The spectrum of attitudes towards air travel and climate change found amongst the study participants suggests there may be a need for stronger messages from government and the media on air travel's climate impact if the UK government seeks consumer behavioural change to help meet its climate change targets. Gössling et al. (2008) noted that media reports on the environmental impacts of air travel may affect air travel-based tourism in the future as the travel behaviour of environmentally aware tourists are affected. In a potentially powerful analogy, William (42) related how reduced air travel might be encouraged through a similar approach as to how the dangers of smoking were addressed:

It's just like smoking. It needs to be emphasised more and make people realise the impact that they can have by travelling by plane. I think they need to come down with concrete numbers that people can relate to. But until that happens, we're just going to go with everyone else and go with the cheap option and the convenient option which is to fly.

William's comment echoes Mark Ellingham, founder of the Rough Guides, who issued a pejorative critique of frequent flying in which he referred to it as 'the new tobacco' (Hill, 2007 in Randles and Mander, 2009). Indeed, such critiques and other negative 
portrayals of air travel's emissions, as seen for instance in the 2009 film The Age of Stupid, may help to nudge UK consumers towards air travel with a conscience.

The question has been raised of how governments can educate and encourage their citizens towards reduced air travel without market-based pricing mechanisms that are socially exclusive (Shaw \& Thomas, 2006). Hares et al. (2009), hoping to combat the information deficit between tourism and climate change, have called for accessible and relevant information to be presented to the general public regarding the scale of climate impact from air travel. Ruby (41) cited the need for more concrete and accessible numbers on air travel emissions:

Perhaps if somebody showed me - of your daily living you're using the equivalent of a year's worth to travel there - maybe that would make me rethink. There's nowhere easily or obviously available where they give you specific facts. I think it's easy at the moment for me to ignore, to know that it's bad, but I don't know how bad.

Indeed, if the UK media were to stress that one return flight from the UK to NZ equates to approximately $44 \%$ of each UK citizen's yearly domestic $\mathrm{CO}_{2}$ emissions and $120 \%$ of yearly sustainable emissions, such statistics could induce behavioural change in the UK, but would also pose a significant threat to the viability of the UK long haul market for the NZ tourism industry.

Lack of public awareness on the climate impact of air travel has been attributed to the aviation industry putting itself in a positive environmental light (Gössling \& Peeters, 2007). Counteracting these industry discourses may need to go beyond the popular press and be more formally politicised. As Thomas (38) stressed, climate change education through the television may not be enough: 
I need someone to reinforce the message to me of the implications. Somebody tell me in whatever mediums they're going to reach me to give me the information. I don't get any leaflets through the door now from the council really telling me about it. All I see is through educating myself through watching the tele.

Although Becken (2007) has cautioned that information on its own may not be sufficient to induce behavioural change in air travel patterns, in Jack's (35) case, media coverage is in fact affecting his conscience: 'Since it's been in the media more and I've been more aware of it, I've been more conscientious with regards to where I travel, even how I drive my car. My behaviour has changed more with having more knowledge.'

\section{Conclusion}

Amidst growing tensions between air travel and sustainable emission levels, this article has assessed UK consumer perceptions towards long haul air travel to NZ. In doing so, the research has made apparent a spectrum of attitudes towards air travel's climate impact from amongst its UK study participants. Albeit a few of the interviewees were still relatively unaware of air travel's contribution to climate change and many others were aware but unwilling to rein in their aeromobilities, a significant number of the participants expressed the view that they were aware of the impact and were beginning to consume air travel with a carbon conscience. Respondents evidencing awareness of and growing response to air travel's climate impact add empirical support to recent studies suggesting that tourists are increasingly concerned over air travel's $\mathrm{CO}_{2}$ emissions (Gössling, et al., 2009; Gössling, et al., 2008; Randles \& Mander, 2009).

Although interviewees were concerned about the volume of emissions involved in flying to NZ, little evidence was found that these UK consumers would forgo an air 
trip to NZ because of climate concern. Whereas long haul travel to NZ was justified as extraordinary, in contrast, frequent short haul air trips within the UK and Europe were implicated by the respondents as more problematic for climate change. Interviewee indictments of impulsive short haul air travel, alongside media comparisons of frequent flying to the tobacco industry, suggest that further research is needed into UK attitudes towards short haul air travel and climate change. Theories on addiction may prove to be an interesting tool for analysing social dependencies on frequent short haul air travel.

In a parallel study of Norwegian consumer attitudes towards long haul travel to $\mathrm{NZ}$, in which a shift towards air travel with a conscience is more widely apparent than in the UK, Higham and Cohen (in press) found significant travel behaviour modifications taking place due to climate concern. Cultural differences between the UK and Norway notwithstanding, while NZ's largest long haul market may not yet be redirecting their holidays away from NZ because of climate concern over air travel, any further movement within this source market towards consuming air travel with a conscience could pose significant challenges for NZ tourism. This may especially be the case if the UK strengthens initiatives to further education and media messages about air travel's climate impact. Indeed, the current research demonstrates that some are already calling for more concrete information on air travel's emissions upon which to base more informed travel decisions. Besides the need for longitudinal research that continues to track potential changes in climate concern and perceptions of air travel in the UK market, especially as recent major global events such as the COP15 United Nations Climate Change Conference occupy media headlines, future comparative research is needed into consumer perceptions in NZ's other major inbound tourism markets. Such 
lines of research are imperative if NZ, a geographically remote island destination, seeks to maintain a competitive and sustained international tourism profile.

\section{References}

Becken, S. (2002). Analysing International Tourist Flows to Estimate Energy Use Associated with Air Travel. Journal of Sustainable Tourism, 10(2), 114-131.

Becken, S. (2004). How tourists and tourism experts perceive climate change and carbonoffsetting schemes. Journal of Sustainable Tourism, 12(4), 332-345.

Becken, S. (2007). Tourists' Perception of International Air Travel's Impact on the Global Climate and Potential Climate Change Policies. Journal of Sustainable Tourism, 15, 351-368.

Bows, A., Anderson, K., \& Footitt, A. (2009). Aviation in a low-carbon EU. In S. Gössling \& P. Upham (Eds.), Climate change and aviation: Issues, challenges and solutions (pp. 89109). London: Earthscan.

Bows, A., Anderson, K., \& Upham, P. (2006). Contraction \& convergence: UK carbon emissions and the implications for UK air traffic (Tyndall Centre Technical Report, No 40) Norwich: Tyndall Centre for Climate Change Research.

Brand, C., \& Boardman, B. (2008). Taming of the few - the unequal distribution of greenhouse gas emissions from personal travel in the UK. Energy Policy, 36, 224-238.

Donnelly, D. (2008). Propensity for UK and German travelers to adapt travel intentions due to rising awareness of climate change issues: Prepared by Instinct and Reason for Department of Resources, Energy and Tourism, Surry Hills, NSW.

Dubois, G., \& Ceron, J. P. (2006). Tourism/leisure greenhouse gas emission forecasts for 2050: Factors for change in France. Journal of Sustainable Tourism, 14(2), 172-191.

Gössling, S. (2009). Carbon neutral destinations: a conceptual analysis. Journal of Sustainable Tourism, 17(1), 17-37.

Gössling, S., Bredberg, M., Randow, A., Sandström, E., \& Svensson, P. (2006). Tourist perceptions of climate change: a study of international tourists in Zanzibar. Current Issues in Tourism, 9(4\&5), 419-435.

Gössling, S., Haglund, L., Kallgren, H., Revahl, M., \& Hultman, J. (2009). Swedish air travellers and voluntary carbon offsets: towards the co-creation of environmental value. Current Issues in Tourism, 12(1), 1-19.

Gössling, S., \& Hall, C. M. (2006). Uncertainties in predicting tourist flows under scenarios of climate change. Climatic Change, 79(3), 163-173.

Gössling, S., \& Hall, C. M. (2008). Swedish Tourism and Climate Change Mitigation: An Emerging Conflict? Scandinavian Journal of Hospitality and Tourism, 8(2), 141-158.

Gössling, S., \& Peeters, P. (2007). 'It Does Not Harm the Environment!' An Analysis of Industry Discourses on Tourism, Air Travel and the Environment. Journal of Sustainable Tourism, 15, 402-417.

Gössling, S., Peeters, P., \& Scott, D. (2008). Consequences of Climate Policy for International Tourist Arrivals in Developing Countries. Third World Quarterly, 29(5), 873-901.

Gössling, S., \& Upham, P. (Eds.). (2009). Climate change and aviation: Issues, challenges and solutions. London: Earthscan.

Hares, A., Dickinson, J., \& Wilkes, K. (2009). Climate change and the air travel decisions of UK tourists. Journal of Transport Geography, 18(3), 466-473. 
Hill, A. (2007). Travel: the new tobacco Retrieved 11 November, 2009, from http://www.guardian.co.uk/travel/2007/may/06/travelnews.climatechange?print

Higham, J.E.S., \& Cohen, S. (in press). Canary in the coalmine: Norwegian attitudes towards climate change and extreme long-haul air travel to Aotearoa/New Zealand. Tourism Management.

Jennings, G. (2001). Tourism Research. Milton: John Wiley \& Sons.

Lise, W., \& Tol, R. S. J. (2002). Impact of climate on tourist demand. Climatic Change, 55, 429-449.

Ministry of Tourism (2008). New Zealand tourism and climate change plan. New Zealand: Ministry of Tourism.

Ministry of Tourism (2009a). Summary forecasts - national Retrieved 11 November, 2009, from http://www.tourismresearch.govt.nz/Documents/Forecasts\%20Summary/Forecasts2009 -2015/Summary\%20\%20National\%20Inbound\%20Forecasts\%20by\%20Market\%202009-2015.pdf

Ministry of Tourism (2009b). International visitors - United Kingdom Retrieved 11 November, 2009a, from http://www.tourismresearch.govt.nz/Documents/Internationa1\%20Market\%20Profiles/U K\%20Profile.pdf

Monbiot, G. (2007). Heat: How to stop the planet burning. London: Penguin Books.

Penner, J. E., Lister, D. H., Griggs, D. J., Dokken, D. J., \& McFarland, M. (1999). Aviation and the global atmosphere - a special report of IPCC working groups I and III. Cambridge: Intergovernmental panel on climate change.

Randles, S., \& Mander, S. (2009). Practice(s) and ratchet(s): A sociological examination of frequent flying. In S. Gössling \& P. Upham (Eds.), Climate change and aviation: Issues, challenges and solutions (pp. 245-271). London: Earthscan.

Shaw, S., \& Thomas, C. (2006). Discussion Note: Social and Cultural Dimensions of Air Travel Demand: Hyper-Mobility in the UK? Journal of Sustainable Tourism, 14(2), 209-215.

Smith, I. J., \& Rodger, C. J. (2009). Carbon offsets for aviation-generated emissions due to international travel to and from New Zealand. Energy Policy, 37, 3438-3447.

Vertovec, S. (2009). Transnationalism. London: Routledge. 